\title{
Predictors of thickened carotid intima media thickness among well controlled lupus nephritis patients in a Malaysian tertiary centre
}

\author{
S.S. Shaharir, M.S. Mohamed Said, N.C.T. Kong \\ Department of Medicine, Kebangsaan University Malaysia Medical Centre, \\ Jalan Yaacob Latif, Bandar Tun Razak, Cheras Kuala Lumpur, Malaysia
}

\begin{abstract}
SUMMARY
Objectives. To investigate the prevalence of thickened carotid intima media thickness (CIMT) and its associated risk factors in patients with lupus nephritis $(\mathrm{LN})$ who were in remission.

Methods. This was a cross sectional study in which consecutive LN patients who were in remission and attending our Nephrology/SLE Clinic were included. Their demographic profile, traditional cardiovascular risk factors and treatment medications were evaluated by clinical interview and review of medical records. Carotid intima media thickness (CIMT) was measured using B Mode carotid ultrasonography. CIMT was considered to be abnormally thickened if it exceeded the $75^{\text {th }}$ percentile matched for age-and sex-matched normal controls. The associated factors for thickened CIMT were examined.

Results. A total of 39 patients with a mean remission duration of $29 \pm 24.3$ months and on a mean prednisolone dose of $9.10 \pm 7.83 \mathrm{mg}$ daily completed the study. Six patients $(15.4 \%)$ had thickened CIMT. On univariate analysis, male gender, patient age, older age at diagnosis, higher serum CRP levels, greater proteinuria and higher mean cumulative azathioprine dose were associated with thickened CIMT $(\mathrm{P}<0.05)$. Lower mean cumulative doses of cyclosporine A (CyA) and mycophenolic acid (MPA) $(\mathrm{P}<0.05)$ each were associated with thickened CIMT. Using regression analysis, the associated factors of CIMT were older age at diagnosis and proteinuria. Conclusions. Lupus factors particularly age at diagnosis and proteinuria were the associated factors of thickened CIMT. Larger prospective trials are indicated to confirm our findings.
\end{abstract}

Key words: Lupus nephritis, carotid intima media thickness (CIMT), remission, proteinuria.

Reumatismo, 2012; 64 (6): 341-349

\section{INTRODUCTION}

ystemic lupus erythematosus (SLE) patients are at risk for premature cardiovascular disease (CVD) consistent with the recent paradigm shift towards the concept of atherosclerosis as a consequence of vascular inflammation. Urowitz et al. first highlighted the bimodal mortality pattern of SLE patients in whom mortality was due not only to acute flares of the disease and/or infections but also to CVD and its complications occurring several years later (1). Subsequent studies consistently showed a similar pattern of mortality but most of these were almost exclusively from the developed countries (2-4). Although there is scarce data on the CVD burden among Asian lupus populations, a few recent studies suggested that CVD has emerged as a significant threat to their survival especially with advances in the overall management of SLE patients (5-7). Reports from Singapore, India, Korea, China and Hong Kong estimated the prevalence of death from vascular complications in Asian SLE populations to range from 6.5$17 \%$ (8).

In general, SLE patients from South East Asia are more disposed to develop renal disease compared to Caucasians and the prevalence has been reported to be as high as $64-74 \%(9,10)$ vs $27.9 \%$ in European studies (11). SLE patients, particularly those with LN have a higher prevalence of traditional cardiovascular risk factors such
Corresponding author: Dr. Syahrul Sazliyana Shaharir Department of Medicine Kebangsaan University Malaysia Medical Centre Jalan Yaacob Latif Bandar Tun Razak 52100 Cheras Kuala Lumpur, Malaysia E-mail: sazliyana@hotmail.com 
as hypertension, dyslipidemia, chronic kidney disease (CKD) and end stage renal disease (ESRD) $(12,13)$. However, most studies found that traditional cardiovascular risk factors alone failed to explain the excess cardiovascular risk among the lupus patients (14-16). Few studies have examined the CVD burden and its associations in patients with lupus nephritis per se (17, 18 ), as most involved a fairly heterogenous group of SLE patients.

In addition, CKD itself is also associated with increased CV mortality, up to $10-20$ times that in the general population (19). Using CIMT, a proven excellent predictor of future CVD events (20), we evaluated the CVD risk in a homogenous group of LN patients who were in disease remission.

\section{METHODS}

Consecutive lupus patients with LN aged 16 years who were not pregnant or with inadequate clinical conditions at the time of study were recruited from June 2009 to February 2010. LN was diagnosed by renal biopsy or clinically by the presence of proteinuria of $\geq 0.5 \mathrm{~g} /$ day with or without cylindruria accompanied by positive serology (hypocomplementemia and/or elevated anti-nuclear antibody and/or positive for-dsDNA antibodies) (21). We selected patients who were in complete remission, which was defined as:

1. an estimated GFR (eGFR) $\geq 60 \mathrm{mls} /$ $\min / 1.73 \mathrm{~m}^{2}$ or $>25 \%$ increase from baseline;

2. proteinuria of $\leq 0.5 \mathrm{~g} /$ day or urine protein-creatinine index $<0.05 \mathrm{~g} / \mathrm{mmol}$;

3 . urinary red cells less than five red blood cells (high power field);

4. no cellular casts in the urine $(22,23)$. All subjects were given a detailed explanation of the study and informed consent was obtained. Informed consent from patients aged $<18$ years were taken from parents/caretakers.

This prospective study was approved by the local Research and Ethics Committee under the grant FF027 2009.
After informed consent, a clinical interview and physical examination were conducted on all subjects by the principal investigator to ascertain their demographics and to identify the traditional cardiovascular risk factors and lupus/disease factors present in each patient. Blood and urine investigations were performed to assess for the traditional cardiovascular risk factors and activity of their SLE/LN.

These included full blood count (FBC), renal profile (RP), liver function test (LFT), C-reactive protein (CRP), C3 and C4 levels, antinuclear antibody, anti-double stranded DNA (ds DNA), anti-cardiolipin antibodies (aCL $\operatorname{IgG}$ and $\operatorname{IgM}$ ), lupus anticoagulant (LA), fasting serum lipids (FSL), fasting blood glucose (FBG) and $\mathrm{HbA1C}$, urine examination for protein and red blood cells and urine protein- creatinine index (uPCI). Their estimated glomerular filtration rate (eGFR) was calculated using the Modification of Diet in Renal Disease (MDRD) formula (24).

The eGFR was derived using the following (MDRD) equation:

$$
\begin{gathered}
\mathrm{eGFR}=32788 \mathrm{x} \\
\text { serum creatinine } \mathrm{e}^{-1.154}(\mu \mathrm{mol} / \mathrm{L}) \mathrm{x} \operatorname{age}^{-0.203} \mathrm{x} \\
{[0.742 \text { if female }] .}
\end{gathered}
$$

Further history regarding previous cardiovascular events - defined as any history of coronary event such as myocardial infarction (MI), angioplasty or coronary artery bypass surgery and cerebrovascular accidents (CVAs) - were obtained from the patient and the medical records. Diabetes mellitus was diagnosed according to the American Diabetes Association and was defined by a fasting plasma glucose of $\geq 7$ $\mathrm{mmol} / \mathrm{L}$ or two hours post-prandial glucose of $\geq 11.1 \mathrm{mmol} / \mathrm{L}$ (25), or current use of anti-diabetic agents. Hypertension was defined as systolic arterial pressure $>140$ $\mathrm{mmHg}$ and/or diastolic arterial pressure above $90 \mathrm{mmHg}$, or current use of antihypertensive drugs prescribed with the aim to reduce blood pressure (26). Dyslipidemia was diagnosed if plasma cholesterol exceeded $6.19 \mathrm{mmol} / \mathrm{L}$, plasma LDL cholesterol $4.12 \mathrm{mmol} / \mathrm{L}$, plasma triglycerides $2.3 \mathrm{mmol} / \mathrm{L}(26)$ or when the patients 
used HMG-CoA inhibitors. Abdominal obesity was defined as waist circumference of $\geq 80 \mathrm{~cm}$ for females and $\geq 90 \mathrm{~cm}$ for males (27). Patients with a body mass index (BMI) of $\geq 23 \mathrm{~kg} / \mathrm{m}^{2}$ were classified as overweight, whilst those with BMI $>25$ $\mathrm{kg} / \mathrm{m}^{2}$ as obese according to Asian Pacific Guidelines (28).

The specific treatment and immunosuppressive regimen received by each patient was obtained from their medical records and outpatient clinic prescriptions. The cumulative dose and duration of steroids, cyclophosphamide, cyclosporine A (CyA), mycophenolic acid (Cellcept or Myfortic), azathioprine and hydroxychloroquine were calculated. The disease damage scores were measured with the Systemic Lupus International Collaborating Clinics damage index (SLICC) 1996 (29).

The ultrasound of the common carotid artery (CCA) - performed according to the standard protocol described in the American Echocardiographic Guidelines (30) - was used to measure the CIMT and carotid atherosclerosis. The examination was performed with an ultrasound scanner (Siemens SONOLINE G40) with a 7-MHz linear transducer and a transducer aperture of $38 \mathrm{~mm}$. The right and left carotid arteries were scanned at the level of the bifurcation. Images for carotid intima media thickness (CIMT) measurements were recorded from the carotid bulb and it was defined as the distance from the leading edge of the lumen-intima interface to the leading edge of the media-adventitia interface of the far wall. The CIMT was measured at $1 \mathrm{~cm}$ proximal to the start of the carotid bulb dilatation of the common carotid artery (CCA) in the far wall and the maximum CIMT value was recorded. Since there are no local references for CIMT values for our level young population, the CIMT values of age- and sexmatched controls from the Carotid Atherosclerosis Progression Study (CAPS) (31) were used. The CAPS has been duly recognized by the American Echocardiographic Society (30).

These regions of the carotids were also scanned longitudinally to assess the occur- rence of plaques. If a plaque was present, a frozen B-mode image of the thickest part of the plaque in the longitudinal view was recorded on videotape. A short sequence of real-time images was also recorded to assist in the interpretation of the frozen images. CIMT of $\geq 75^{\text {th }}$ percentile for the patient's age and sex was considered to be abnormally thickened (30). The carotid ultrasound was performed by the principal investigator. All the findings were verified by an experienced neurosonographer who was blinded to all the cases.

\section{Statistical analysis}

Normality test was done for all the study variables. All normally distributed numerical parameters were expressed as mean \pm SD (standard deviation) and were analyzed with parametric tests ie ANOVA (for more than 2 variables) and Student's $t$-test (for 2 variables).

Non-normally distributed parameters were expressed as median interquartile range (IQR) and were analyzed with non-parametric tests, i.e. Mann-Whitney U-test for numerical data and $\chi^{2}$ for categorical data. Significance was taken as $\mathrm{P} \leq 0.05$. Forward logistic regression analysis was performed to determine the best model of independent predictors for thickened CIMT in LN patients. The SPSS V18.0 statistical package was used.

\section{RESULTS}

A total of 39 patients with $\mathrm{LN}$ and a mean duration of disease remission of $28.9 \pm 24.3$ months completed the study. The patients' mean age was $35.2 \pm 11.2$ years. There were $20(51.3 \%)$ Malays followed by 15 (38.5\%) Chinese and four (10.3\%) Indians, reflecting their ethnic composition in the general Malaysian population. Twenty four $(61.5 \%)$ of them were hypertensive and 15 (38.5\%) had dyslipidaemia. Only five patients $(12.8 \%)$ had diabetes mellitus, one $(2.6 \%)$ had a history of cerebrovascular accident (CVA) and none of them smoked nor had a history of ischaemic heart disease. Six $(15.4 \%)$ female patients were post- 
menopausal. 33 (84.6\%) of them had renal biopsy and majority were Class IV $(\mathrm{n}=16$, $41 \%)$, followed by Class III $(n=11,28.2 \%)$ and Class V ( $\mathrm{n}=6,15.4 \%)$; according to the World Health Organization Classification 1995. Six $(15.4 \%)$ of them refused renal biopsy.
The median SLEDAI score was 2 (IQR 4) and the mean current daily prednisolone dose was $9.10 \pm 7.83 \mathrm{mg}$. The cardiovscular risk profile and lupus characteristics of the LN patients are summarized in Table I.

Compared with age- and sex- matched controls from the Carotid Atherosclerosis

Table I - Comparison of the demographic profiles, traditional cardiovascular risk factors and lupus characteristics between LN patients with normal vs thickened CIMT.

\begin{tabular}{|c|c|c|c|}
\hline Parameters & Normal CIMT $n=33$ & Thickened CIMT $\mathrm{n}=6$ & P-value \\
\hline Current age (years) & $33.0 \pm 10.3$ & $47.5 \pm 7.7$ & $<0.01$ \\
\hline Disease duration (years) & $7.9 \pm 5.9$ & $8.4 \pm 4.6$ & 0.86 \\
\hline Duration of remission (months) & $28.8 \pm 22.9$ & $29.3 \pm 33.2$ & 0.90 \\
\hline Age at diagnosis (years) & $24.3 \pm 7.4$ & $34.2 \pm 9.0$ & $<0.01$ \\
\hline $\begin{array}{l}\text { Gender (\%) } \\
\text { Female } \\
\text { Male }\end{array}$ & $\begin{array}{l}31(88.6 \%) \\
2(50.0 \%)\end{array}$ & $\begin{array}{l}4(11.4 \%) \\
2(50.0 \%)\end{array}$ & 0.04 \\
\hline $\begin{array}{l}\text { Race }(\%) \\
\text { Malay } \\
\text { Chinese } \\
\text { Indian } \\
\text { Body mass index, }\left(\mathrm{kg} / \mathrm{m}^{2}\right) \\
\text { Waist circumference }(\mathrm{cm}) \\
\end{array}$ & \begin{tabular}{|l}
$18(90.0 \%)$ \\
$12(80.0 \%)$ \\
$3(75 \%)$ \\
25.4 (IQR 6.5$)$ \\
81 (IQR 21) \\
\end{tabular} & $\begin{array}{l}2(10.0 \%) \\
3(20.0 \%) \\
1(25 \%) \\
25.2(\text { IQR } 9.1) \\
88.5 \text { (IQR 19) } \\
\end{array}$ & $\begin{array}{l}0.28 \\
\\
0.76 \\
0.37 \\
\end{array}$ \\
\hline $\begin{array}{l}\text { Diabetes mellitus (\%) } \\
\text { Yes } \\
\text { No }\end{array}$ & $\begin{array}{l}3(9.1 \%) \\
30(90.9 \%) \\
\end{array}$ & $\begin{array}{l}2(33.3 \%) \\
4(66.7 \%) \\
\end{array}$ & 0.32 \\
\hline Hypertension (\%) & $19(57.6 \%)$ & $5(83.3 \%)$ & 0.23 \\
\hline Dyslipidaemia (\%) & $12(36.4 \%)$ & $3(50.0 \%)$ & 0.58 \\
\hline $\begin{array}{l}\text { Menopause (\%) } \\
\text { Aspirin use (\%) } \\
\text { Statin use (\%) }\end{array}$ & \begin{tabular}{|l|}
$4(12.1 \%)$ \\
$11(33.3 \%)$ \\
$9(27.3 \%)$ \\
\end{tabular} & \begin{tabular}{|l|}
$2(33.3 \%)$ \\
$3(50 \%)$ \\
$1(16.7 \%)$ \\
\end{tabular} & \begin{tabular}{|l|}
0.19 \\
0.60 \\
0.50 \\
\end{tabular} \\
\hline Systolic blood pressure $(\mathrm{mmHg})$ & $128.2 \pm 14.6$ & $137.2 \pm 17.9$ & 0.19 \\
\hline Diastolic blood pressure $(\mathrm{mmHg})$ & $73.1 \pm 14.5$ & $77.7 \pm 15.5$ & 0.42 \\
\hline $\begin{array}{l}\text { Creatinine }(\mu \mathrm{mol} / \mathrm{L}) \\
\text { eGFR }\left(\mathrm{mL} / \mathrm{min} / 1.73 \mathrm{~m}^{2}\right)\end{array}$ & $\begin{array}{l}63 \text { (IQR 27) } \\
94.0 \pm 29.3\end{array}$ & $\begin{array}{l}79 \text { (IQR 47) } \\
76.3 \pm 20.2\end{array}$ & $\begin{array}{l}0.20 \\
0.17\end{array}$ \\
\hline Triglyceride (mmol/L) & $1.1($ (IQR 0.85$)$ & 1.3 (IQR 0.62) & 0.90 \\
\hline Total cholesterol (mmol/L) & $5.2 \pm 0.9$ & $5.3 \pm 0.8$ & 0.86 \\
\hline $\mathrm{LDL}(\mathrm{mmol} / \mathrm{L})$ & $3.0 \pm 0.8$ & $3.0 \pm 0.8$ & 0.97 \\
\hline $\mathrm{HDL}(\mathrm{mmol} / \mathrm{L})$ & 1.5 (IQR 0.72) & 1.5 (IQR 1.05) & 0.85 \\
\hline Fasting blood sugar (mmol/L) & 4.8 (IQR 0.7) & 5.1 (IQR 1.25) & 0.41 \\
\hline $\mathrm{HbA1c},(\%)$ & 5.5 (IQR 0.7) & 5.7 (IQR 1.3) & 0.54 \\
\hline $\mathrm{CRP}(\mathrm{mg} / \mathrm{dL})$ & 0.13 (IQR 0.15$)$ & 0.31 (IQR 0.75) & 0.03 \\
\hline $\mathrm{ESR} \mathrm{mm} / \mathrm{hr}$ & 24 (IQR 19) & 36.5 (IQR 15.5) & 0.11 \\
\hline C3 (79-152 mg/dL) & $88.0 \pm 40.8$ & $83.7 \pm 44.9$ & 0.79 \\
\hline $\begin{array}{l}\text { C4 (16-38 mg/dL) } \\
\text { uPCl (g/mmol) } \\
\text { SLEDAl score }\end{array}$ & \begin{tabular}{|l|}
$19.3 \pm 10$ \\
0.02 (IQR 0.02) \\
2 (IQR 4) \\
\end{tabular} & $\begin{array}{l}13.4 \pm 8.7 \\
0.04 \text { (IQR 0.03) } \\
2 \text { (IQR 8) } \\
\end{array}$ & \begin{tabular}{|l|}
0.18 \\
0.03 \\
0.90 \\
\end{tabular} \\
\hline aCL IgG or IgM positive (\%) & $8(100)$ & $0(0)$ & 0.30 \\
\hline SLICC Index 1996 (total=47) & 0 (IQR 1) & 0 (IQR 1) & 1.00 \\
\hline
\end{tabular}

$\mathrm{LN}$ = lupus nephritis; CIMT = carotid intima media thickness. * eGFR = estimated glomerular filtration rate; $\mathrm{CRP}=\mathrm{C}$-reactive protein; ESR = Erythrocyte sedimentation rate; $\mathrm{uPCl}=$ urine protein: creatinine index; SLEDAI = systemic lupus erythematosus disease activity index; SLICC = systemic lupus international collaborative clinics. 
Table II - Comparison of mean cumulative dose and duration of immunosuppressive medications received by LN patients with thickened and normal CIMT.

\begin{tabular}{|l|l|l|l|}
\hline Treatment & Normal CIMT & Thickened CIMT & P-value \\
\hline Cumulative dose steroids $(\mathrm{g}) \mathrm{n}=39$ & $21.06 \pm 11.23$ & $23.73 \pm$ QR 10.91 & 0.60 \\
Duration steroids (years) $\mathrm{n}=39$ & $6.35 \pm 4.79$ & $7.02 \pm 4.35$ & 0.70 \\
Current prednisolone $(\mathrm{mg})$ & $9.73 \pm 8.21$ & $5.83 \pm 4.81$ & 0.09 \\
\hline Cumulative IV Methylprednisolone $(\mathrm{g}) \mathrm{n}=36$ & $1.32 \pm 0.88$ & $1.01 \pm 0.76$ & 0.40 \\
\hline Cumulative cyclophosphamide $(\mathrm{g}) \mathrm{n}=32$ & $5.53 \pm 3.19$ & $4.20 \pm 0.85$ & 0.07 \\
\hline Cumulative cyclosporine $\mathrm{A}(\mathrm{g}) \mathrm{n}=22$ & $111.19 \pm 95.31$ & $52.42 \pm 29.62$ & 0.05 \\
\hline Cumulative mycophenolic acid (g), $\mathrm{n}=17$ & $1044.96 \pm 700.19$ & $402.83 \pm 51.04$ & $<0.01$ \\
\hline Cumulative azathioprine $(\mathrm{g}) \mathrm{n}=31$ & $51.84 \pm 40.67$ & $129.01 \pm 91.64$ & $<0.01$ \\
\hline Cumulative hydroxychloroquine (g) $\mathrm{n}=21$ & $254.17 \pm 175.94$ & $143.30 \pm 68.54$ & 0.09 \\
\hline
\end{tabular}

$\mathrm{LN}=$ lupus nephritis; CIMT = carotid intima media thickness.

Table III - Logistic regression analysis, adjusted for age and sex.

\begin{tabular}{|l|l|l|l|}
\hline Variables & B Coefficients & Odds ratio (95.0\% Confidence interval) & P-value \\
\hline Age at diagnosis & 0.36 & $1.44(1.04-1.98)$ & 0.02 \\
\hline uPCl (g/mmol creatinine) & 0.32 & $4.52(1.09-7.96)$ & 0.01 \\
\hline
\end{tabular}

Adjusted $\mathrm{R}$ square 0.53 . $\mathrm{uPCl}=$ urine protein creatinine index.

Progression Study (CAPS) and using $75^{\text {th }}$ percentile as the cut off, six $(15.4 \%) \mathrm{LN}$ patients had thickened CIMT. The mean CIMT of the LN cohort was 0.5 (IQR 0.2) $\mathrm{mm}$. Patients with thickened CIMT were significantly $(\mathrm{P}<0.01)$ older than those with normal CIMT $(42.4 \pm 7.8$ years vs $31.9 \pm 9.5$ years). Male patients had significantly thicker median CIMT of 0.8 (IQR 0.6) mm compared to 0.5 (IQR 0.2 ) $\mathrm{mm}$ in their female counterparts $(\mathrm{P}<0.05)$. There were no significant differences in the prevalence of traditional cardiovascular risk factors between lupus patients with normal versus thickened CIMT (Tab. I).

Among lupus disease characteristics, older age at diagnosis, higher serum CRP and greater degree of proteinuria were significantly associated with thickened CIMT (Tab. I). All patients with the antiphospholipid syndrome $(n=4)$ had a normal CIMT. No association was found between thickened CIMT with duration of disease and serum complement levels. There were also no association between thickened CIMT and the number of disease relapse and LN class (WHO classification of 1995).

There were also no differences in the cumulative steroid dose between patients with normal or thickened CIMT. Among patients who received CyA $(n=22)$ and
MMF ( $\mathrm{n}=17)$, those with thickened CIMT received a lower cumulative dose of the respective immunosuppressive agents compared to those with thickened CIMT $(\mathrm{P}<0.05)$. On the other hand, among patients who had received azathioprine $(\mathrm{n}=31)$, those with thickened CIMT received a higher cumulative azathioprine dose $(\mathrm{P}<0.05)$ (Tab. II).

Regression analysis was used to examine demographic variables, lupus characteristics traditional CVD risk factors and immunosuppressive use that were significantly more common in patients with thickened CIMT than those with normal CIMT. All the variables which were significantly correlated or associated with CIMT during univariate analysis $(\mathrm{P}<0.05)$ were included in the analysis. From the analysis, the best model of the independent predictors of CIMT were advanced age at diagnosis and higher urine protein-creatinine index (Tab. III).

\section{DISCUSSION}

Renal involvement in Systemic Lupus Erythematosus (SLE) is associated with premature atherosclerosis (17). This is the first study assessed the prevalence and 
factors associated with thickened CIMT among LN patients who were in remission in Malaysia. In addition to the traditional CVD risk factors, lupus specific factors and the type of immunosuppressive agents used in the treatment of $\mathrm{LN}$ were also found to impact the cardiovascular risks and CIMT them.

The prevalence of thickened CIMT among our cohort was $15.4 \%$ and this was lower compared to those reported in Caucasian patients wits SLE. Focal plaques were detected in $40 \%$ of both the Pittsburgh lupus cohort $(n=175)$ (32) and that reported by Roman et al. $(\mathrm{n}=197)$ (33) in New York. However, the mean ages of their lupus patients were 45 and 44 years respectively, whereas our LN patients were a decade younger (35.2 \pm 11.2 years). Additionally, $12 \%$ of patients in the Pittsburgh lupus cohort and $15 \%$ of the New York cohort had a previous history of cardiovascular events compared to only $2.6 \%$ in our study.

There is a paucity of information on the prevalence of atherosclerosis in Asian lupus patients. Bhatt et al. reported that seven of $(14 \%)$ of their 50 Asian Indian patients with a mean age of $31.6 \pm 10$ years had at least a focal carotid plaque (7). Despite almost similar mean ages in our two Asian studies, the higher frequency of carotid plaques in the Asian Indians can be explained by ethnicity as Asian Indians are known to be more susceptible to cardiovascular disease compared with other Asian ethnic populations (34). Besides sociodemographic backgrounds, differences in the definition of thickened CIMT and carotid plaques as well as other pertinent technical respects may also account for the dissimilar reported prevalences. Some studies used the cut-off point of $0.9 \mathrm{~mm}$ (35) to define thickened CIMT whilst other workers used $>1 \mathrm{~cm} \mathrm{(36)}$ or $>1.3 \mathrm{~cm}(37,38)$ to define significant carotid plaques. Since there are no local references for CIMT in young people, we used the CIMT age and sex matched controls from the Carotid Atherosclerosis Progression Study (CAPS) (31). In this study, various factors were found to be associated with the increased CIMT in LN patients. Despite a high prevalence of traditional CVD risk factors among our LN patients such as hypertension $(61.5 \%)$ and dyslipidaemia (38.5\%), these were not significantly associated with thickened CIMT. These modifiable cardiovascular risk factors had been tightly controlled with antihypertensive agents such as the angiotensin converting enzyme inhibitors (ACEIs) or angiotensin receptor blockers (ARBs) and statins.

In our patients, a greater degree of proteinuria, measured by the urine protein creatinine index (UPCI,) was found to be associated with thickened CIMT. It is well established that nephrotic range proteinuria in SLE is an important risk factor for premature atherosclerosis $(18,39,40)$ partly due to their association with dyslipidemia and hypertension. However, a median proteinuria of as low as $400 \mathrm{mg} /$ day (uPCI 0.04) among our well controlled LN patients was significantly associated with thickened CIMT. It is of utmost importance to ensure that in the management of lupus nephritis, proteinuria should be brought down within the normal range $(<200 \mathrm{mg} /$ day) in order to reduce the risk of premature atherosclerosis.

Among other lupus specific characteristics, older age at diagnosis was also found to be one of the significant association of thickened CIMT among our LN population. Several earlier investigators have reported similar findings $(32,33,41,42)$. To date, a recent large multinational cohort of 1249 SLE patients who were followed up for 8 years also demonstrated that older age at diagnosis was an independent predictor of vascular events associated with atherosclerosis (43). This may be explained by the fact that the younger lupus patients usually present with more acute manifestations thus bringing them to medical attention at an early stage. Whereas late onset disease tends to occur more insidiously and is characterized by nonspecific symptoms for prolonged periods $(44,45)$. This leads to late diagnosis in patients with the reported delay varying from 5 to 60 months (46). We therefore postulated that during the extended period of unrecognized and unsuppressed chronic active inflammation 
of lupus in these older subjects, subclinical atherogenesis may well have already occured even before the diagnosis of SLE was made - a situation similar to the prediabetic phase of Type 2 diabetes mellitus. The antiphospholipid syndrome (aPLS) is well known to be associated with cardiovascular disease by causing interference with the coagulation cascade and the aPL antibodies have a direct damaging effect on endothelial cells which in turn predisposes to thrombogenesis in both the arterial and the venous compartments (47). In our study, the presence of aPLS, serum anticardiolipin antibody (aCL IgG) or lupus anticoagulant (LA) were not found to be associated with thickened CIMT. This may be due to the small sample size and the fact that these autoantibodies were measured at one timepoint and thus did not take into account the possible changing of titres during the course of the disease.

Premature atherosclerosis in LN is multifactorial in aetiology and the treatment with various immunosuppressive medications may contribute to the increased cardiovascular risk in these patients. Among all the immunosuppressants used in the treatment of lupus, corticosteroids are the most commonly studied drug. Numerous studies have demonstrated the association between corticosteroids with increased risk of CVD among lupus patients $(37,41,48)$. However, a higher cumulative dose of corticosteroids generally reflects the severity of the underlying lupus and Manzi et al. has suggested that aggressive disease was the greater determinant of atherosclerosis in lupus as it is now well recognized that atherogenesis itself is an inflammatory state (49). In our study, we did not find any association between cumulative dose of corticosteroids and thickened CIMT. This was probably due to the small sample size and the cumulative doses of corticosteroids were calculated retrospectively from the medical records. Hence, they may not reflect the actual doses taken by the patients, in particular, among those with compliance issues. In our cohort, the mean cumulative dose of corticosteroids prescribed were also lower at $20 \mathrm{~g}$ compared to a prospec- tive study by Doria et al., who found that carotid plaques were associated with cumulative corticosteroids in excess of $40 \mathrm{~g}$ (37). We prefer to introduce immonusuppressive agents early in severe LN than use high oral steroid doses. We also use minipulse methylprenisolone $(250 \mathrm{mg}$ daily $\mathrm{x}$ 3 days) for initial remission reduction so as to obviate increase in infection risk as reported by Paton et al. in a study of local patients (50).

In our study, the use of CyA and MMF was associated with normal CIMT while azathioprine was associated with thickened CIMT. However, these associations were no longer significant in the logistic regression analysis and this could be attributed to the small sample size. The true contributions of these steroids sparing agents towards cardiovascular risks remain largely unknown but the LUMINA paediatric lupus cohort did demonstrate the potential role of azathioprine as a predictor of atherosclerosis (51) and vascular events (52). As this was a cross sectional study we could not determine the causal relationship between atherosclerosis and the various risk factors. It was also difficult to accurately quantity the cumulative doses of each immunosuppressive agent used.

\section{CONCLUSIONS}

This study has demonstrated that lupus factors particularly older age at diagnosis and proteinuria were the important and significant associated factors of subclinical atherosclerosis among patients with well controlled LN. Proteinuria of as low as $400 \mathrm{mg}$ /day was significantly associated with thickened CIMT, therefore it suggests that aggressive treatment of the underlying $\mathrm{LN}$ to achieve complete remission may decrease the likelihood of premature atherosclerosis.

A larger prospective randomized controlled study is indicated to further delineate these exciting relations discussed above.

Conflict of interest: the authors declare no conflict of interests. 


\section{REFERENCES}

1. Urowitz MB, Bookman AA, Koehler BE, et al. The bimodal mortality pattern of systemic lupus erythematosus. Am J Med. 1976; 60: 221-5.

2. Bernatsky S, Boivin JF, Joseph L, et al. Mortality in systemic lupus erythematosus. Arthritis Rheum. 2006; 54: 2550-7.

3. Abu-Shakra M, Urowitz MB, Gladman DD, Gough J. Mortality studies in systemic lupus erythematosus. Results from a single center. II. Predictor variables for mortality. J Rheumatol. 1995; 22: 1265-70.

4. Abu-Shakra M, Urowitz MB, Gladman DD, Gough J. Mortality studies in systemic lupus erythematosus. Results from a single center. I. Causes of death. J Rheumatol. 1995; 22: 1259-64.

5. Sato H, Miida T, Wada Y, et al. Atherosclerosis is accelerated in patients with long-term well-controlled systemic lupus erythematosus (SLE). Clin Chim Acta. 2007; 385: 35-42.

6. Fukumoto S, Tsumagari T, Kinjo M, Tanaka K. Coronary atherosclerosis in patients with systemic lupus erythematosus at autopsy. Acta Pathol Jpn. 1987; 37: 1-9.

7. Bhatt SP, Handa R, Gulati GS, et al. Atherosclerosis in Asian Indians with systemic lupus erythematosus. Scand J Rheumatol. 2006; 35 : 128-32.

8. Navarra SV, King JO. An overview of clinical manifestations and survival of systemic lupus erythematosus patients in Asia. Clinical manifestations and outcome of lupus in asia. APLAR J Rheumat. 2006; 9: 336-41.

9. Boey ML, Peebles CL, Tsay G, et al. Clinical and autoantibody correlations in Orientals with systemic lupus erythematosus. Ann Rheum Dis. 1988; 47: 918-23.

10. Lee SS, Li CS, Li PC. Clinical profile of Chinese patients with systemic lupus erythematosus. Lupus. 1993; 2: 105-9.

11. Cervera R, Font J, Shoenfeld Y. European working party on systemic lupus erythematosus: a 15-year report. Autoimmun Rev. 2006; 5: 549-53.

12. Font J, Ramos-Casals M, Cervera R, et al. Cardiovascular risk factors and the long-term outcome of lupus nephritis. QJM. 2001; 94: 19-26.

13. Chung CP, Avalos I, Oeser A, et al. High prevalence of the metabolic syndrome in patients with systemic lupus erythematosus: association with disease characteristics and cardiovascular risk factors. Ann Rheum Dis. 2007; 66: 208-14.

14. Esdaile JM, Abrahamowicz M, Grodzicky T, et al. Traditional Framingham risk factors fail to fully account for accelerated atherosclerosis in systemic lupus erythematosus. Arthritis Rheum. 2001; 44: 2331-7.
15. Bessant R, Hingorani A, Patel L, et al. Risk of coronary heart disease and stroke in a large British cohort of patients with systemic lupus erythematosus. Rheumatology (Oxford). 2004; 43: 924-9.

16. Goldberg RJ, Urowitz MB, Ibanez D, et al. Risk factors for development of coronary artery disease in women with systemic lupus erythematosus. J Rheumatol. 2009; 36: 2454-61.

17. Serikova S, Kozlovskaia NL, Shilov EM. [Lupus nephritis as a factor of atherosclerosis risk in patients with systemic lupus erythematosus]. [Article in Russian]. Ter Arkh. 2008; 80: 52-8.

18. Falaschi F, Ravelli A, Martignoni A, et al. Nephrotic-range proteinuria, the major risk factor for early atherosclerosis in juvenile-onset systemic lupus erythematosus. Arthritis Rheum. 2000; 43: 1405-9.

19. Foley RN, Parfrey PS, Sarnak MJ. Clinical epidemiology of cardiovascular disease in chronic renal disease. Am J Kidney Dis. 1998; 32 (5 Suppl. 3): S112-9.

20. Lorenz MW, Markus HS, Bots ML, Rosvall M, Sitzer M. Prediction of clinical cardiovascular events with carotid intima-media thickness: a systematic review and meta-analysis. Circulation. 2007; 115: 459-67.

21. Dooley MA, Aranow C, Ginzler EM. Review of ACR renal criteria in systemic lupus erythematosus. Lupus. 2004 ;13: 857-60.

22. Kong NC. Treating lupus: akin to taming of the wolf. Universiti Kebangsaan Malaysia, 2009.

23. Grootscholten C, Ligtenberg G, Hagen EC, et al. Azathioprine/methylprednisolone versus cyclophosphamide in proliferative lupus nephritis. A randomized controlled trial. Kidney Int. 2006; 70: 732-42.

24. Levey AS, Bosch JP, Lewis JB, et al. A more accurate method to estimate glomerular filtration rate from serum creatinine: a new prediction equation. Modification of Diet in Renal Disease Study Group. Ann Intern Med. 1999; 130: 461-70.

25. American Diabetes Association. Diagnosis and classification of diabetes mellitus. Diabetes Care. 2010; 33 (Suppl 1): S62-9.

26. Expert panel on detection, evaluation, and treatment of high blood cholesterol in adults. Executive summary of the third report of the national cholesterol education program (NCEP) expert panel on detection, evaluation, and treatment of high blood cholesterol in adults (adult treatment panel III). JAMA. 2001; 285: 2486-97.

27. WHO, IOTF, IASO. The Asia Pacific perspective: redifining obesity and its treatment. WHO, IOTF and IASO, Hong Kong, 2000.

28. Choo V. WHO reassesses appropriate bodymass index for Asian populations. Lancet. 2002; 360: 235. 
29. Gladman D, Ginzler E, Goldsmith C, et al. The development and initial validation of the Systemic Lupus International Collaborating Clinics/American College of Rheumatology damage index for systemic lupus erythematosus. Arthritis Rheum. 1996; 39: 363-9.

30. Stein JH, Korcarz CE, Hurst RT, et al. Use of carotid ultrasound to identify subclinical vascular disease and evaluate cardiovascular disease risk: a consensus statement from the American Society of Echocardiography $\mathrm{Ca}$ rotid Intima-Media Thickness Task Force. Endorsed by the Society for Vascular Medicine. J Am Soc Echocardiogr. 2008; 21: 93-111; quiz 89-90.

31. Lorenz MW vKS, Steinmetz H, Markus HS, Sitzer M. Carotid intima-media thickening indicates a higher vascular risk across a wide age range: prospective data from the Carotid Atherosclerosis Progression Study (CAPS). Stroke. 2006; 37: 87-92.

32. Manzi S, Selzer F, Sutton-Tyrrell K, et al. Prevalence and risk factors of carotid plaque in women with systemic lupus erythematosus. Arthritis Rheum. 1999; 42: 51-60.

33. Roman MJ, Shanker BA, Davis A, et al. Prevalence and correlates of accelerated atherosclerosis in systemic lupus erythematosus. N Engl J Med. 2003; 349: 2399-406.

34. Emmanuel SC. Trends in coronary heart disease mortality in Singapore. Singapore Med J. 1989; 30: 17-23.

35. Il'ina AE, Kliukvina NG, Aleksandrova EN, et al. Atherosclerotic lesion of the vessels in systemic lupus erythematosus in males: relations with concentration of C-reactive protein. Article in Russian. Ter Arkh. 2005; 77: 61-5.

36. Svenungsson E, Jensen-Urstad K, Heimburger $\mathrm{M}$, et al. Risk factors for cardiovascular disease in systemic lupus erythematosus. Circulation. 2001; 104: 1887-93.

37. Doria A, Shoenfeld Y, Wu R, et al. Risk factors for subclinical atherosclerosis in a prospective cohort of patients with systemic lupus erythematosus. Ann Rheum Dis. 2003; 62: 1071-7.

38. Selzer F, Sutton-Tyrrell K, Fitzgerald SG, et al. Comparison of risk factors for vascular disease in the carotid artery and aorta in women with systemic lupus erythematosus. Arthritis Rheum 2004; 50: 151-9.

39. Theodoridou A, Bento L, D'Cruz DP, et al. Prevalence and associations of an abnormal ankle-brachial index in systemic lupus erythematosus: a pilot study. Ann Rheum Dis. 2003; 62: 1199-203.

40. Manger K, Kusus M, Forster C, et al. Factors associated with coronary artery calcifica- tion in young female patients with SLE. Ann Rheum Dis. 2003; 62: 846-50.

41. Petri M, Perez-Gutthann S, Spence D, Hochberg MC. Risk factors for coronary artery disease in patients with systemic lupus erythematosus. Am J Med. 1992; 93: 513-9.

42. Ahmad Y, Shelmerdine J, Bodill H, et al. Subclinical atherosclerosis in systemic lupus erythematosus (SLE): the relative contribution of classic risk factors and the lupus phenotype. Rheumatology (Oxford). 2007; 46: 983-8.

43. Urowitz MB, Gladman D, Ibanez D, et al. Atherosclerotic vascular events in a multinational inception cohort of systemic lupus erythematosus. Arthritis Care Res (Hoboken). 2010; 62: 881-7.

44. Catoggio LJ, Skinner RP, Smith G, Maddison PJ. Systemic lupus erythematosus in the elderly: clinical and serological characteristics. J Rheumatol. 1984; 11: 175-81.

45. Ramos-Casals M, Garcia-Carrasco M, Brito MP, et al. Autoimmunity and geriatrics: clinical significance of autoimmune manifestations in the elderly. Lupus. 2003; 12: 341-55.

46. Burgos PI, Alarcón GS. Late onset lupus: facts and fiction. Future Rheumatol. 2008; 3: 351-6.

47. Wilson WA, Gharavi AE, Koike T, et al. International consensus statement on preliminary classification criteria for definite antiphospholipid syndrome: report of an international workshop. Arthritis Rheum. 1999; 42: 130911.

48. Manzi S, Meilahn EN, Rairie JE, et al. Agespecific incidence rates of myocardial infarction and angina in women with systemic lupus erythematosus: comparison with the Framingham Study. Am J Epidemiol. 1997; 145: 408-15.

49. Manzi S. Systemic lupus erythematosus: a model for atherogenesis? Rheumatology (Oxford) 2000; 39: 353-9.

50. Paton NI, Cheong I, Kong NC, Segasothy M. Mortality in Malaysians with systemic lupus erythematosus. Med J Malaysia. 1996; 51: 437-41.

51. Schanberg LE, Sandborg C, Barnhart HX, et al. Premature atherosclerosis in pediatric systemic lupus erythematosus: risk factors for increased carotid intima-media thickness in the atherosclerosis prevention in pediatric lupus erythematosus cohort. Arthritis Rheum. 2009; 60: 1496-507.

52. Toloza SM, Uribe AG, McGwin G Jr., et al. Systemic lupus erythematosus in a multiethnic US cohort (LUMINA). XXIII. Baseline predictors of vascular events. Arthritis Rheum 2004; 50: 3947-57. 